quente no sexo masculino, cuja incidência aumenta com a idade e em determinados grupos de risco. A SSJ e a Necrólise Tóxica Epidérmica (NET) são duas entidades da mesma doença, com severidade diferente. A etiologia não é clara, mas pensa-se que se deva maioritariamente a reações adversas a fármacos.

Descrição do caso clínico: Um jovem de 17 anos de idade, sem antecedentes pessoais relevantes, foi observado no Serviço de Urgência por surgimento de lesões maculopapulares, com 3 dias de evolução, dispersas pela face, cavidade oral, tronco e extremidades, com prostração e taquicardia. Foi internado com o diagnóstico de SSJ.

Discussão e conclusões: O SSJ e a NET têm grande morbilidade e considerável mortalidade. O rápido reconhecimento desta identidade, com a remoção do fármaco desencadeador é essencial. A perda da função de barreira da pele, com a consequente alteração da homeostasia, implica muitas vezes a manutenção da terapêutica de suporte em Unidades de Cuidados Intensivos ou de Queimados.

http://doi.org/10.24873/j.rpemd.2017.12.079

\section{\#052 Papiloma escamoso do palato, infantil}

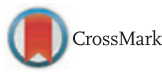

Inês Vaz*, Rosário Malheiro, Ana Fernandes, Jorge Pinheiro, Teresa Corrales, Rafaela Vaz

Hospital de Dona Estefania, Centro Hospitalar de Vila Nova de Gaia e Espinho

Introdução: O papiloma escamoso é uma proliferação benigna do epitélio estratificado, que resulta num aumento de volume papilar ou verruciforme e atinge, mais frequentemente, a língua, os lábios e o palato mole. Existe uma relação clara entre o papiloma escamoso e o vírus do papiloma humano, sobretudo com os serotipos 6 e 11.

Descrição do caso clínico: Trata-se de um caso de papiloma escamoso atingindo o palato duro e o palato mole, num rapaz de 9 anos de idade que se submeteu a biópsias incisionais, seguidas de eletrocauterização das lesões remanescentes. O estudo histológico confirmou o diagnóstico de papiloma escamoso, mas a pesquisa do vírus do papiloma humano por reação de polimerização em cadeia foi negativa. Ao fim de 2 meses, verificou-se restituição ad integrum.

Discussão e conclusões: Apesar de existir uma clara relação etiopatogénica entre o vírus do papiloma humano e o papiloma escamoso, a literatura sugere que a presença do vírus pode ser um achado meramente incidental e permanece a dúvida de que todos os papilomas orais sejam de etiologia vírica. A infeção pelo vírus do papiloma humano é a infeção sexualmente transmissível mais comum, estimando-se que $80 \%$ da população mundial tenha um episódio ao longo da vida. Desde 2017, o Plano Nacional de Vacinação prevê a vacina 'HPV 9', contra 9 serotipos $(6,11,16,18,31$, 33, 45, 52 e 58), aos 10 anos de idade, mas apenas para o sexo feminino. Esta vacina foi aprovada pela 'Food and Drug Administration' para o sexo feminino (dos 9 aos 26 anos) e para o sexo masculino (dos 9 aos 15 anos). A carga de doença pelo vírus, no sexo masculino, é relevante e a forma de reduzir o risco, individualmente, passa pela vacinação. Quando a taxa de cobertura nas raparigas é muito elevada (como acontece em Portugal), os homens beneficiam de imunidade de grupo, mas, numa era de globalização, a circulação entre países pode colocar em risco os não vacinados. Por outro lado, os homens que têm contacto sexual com outros homens não beneficiam significativamente da imunidade de grupo. Assim, atualmente, é recomendada a vacinação dos adolescentes do sexo masculino. Nos doentes com infeção prévia pelo vírus do papiloma humano, parece continuar a haver interesse na vacinação, por ser protetora contra a infeção por outros serotipos.

http://doi.org/10.24873/j.rpemd.2017.12.080

\section{\#053 Ameloblastoma - Uma apresentação em "bolas de sabão"}

Rafaela Vaz*, Lia Jorge, Sónia Viegas, Inês Vaz Silva

Centro Hospitalar de Vila Nova de Gaia/Espinho

Introdução: O Ameloblastoma é o tumor odontogénico clinicamente mais frequente. Este tumor tem origem epitelial e pode ter vários pontos de partida. O Ameloblastoma tem crescimento lento, é localmente invasivo, e detém um curso benigno na maior parte dos casos. Divide-se em Sólido Convencional ou Multiquístico; Uniquístico e Periférico.

Descrição do caso clínico: Doente de 59 anos, género feminino, caucasóide, referenciada à consulta de Estomatologia por queixas inespecíficas em relação com dente 38 - 'dores na gengiva ao mastigar' (sic) -. Ao exame objetivo extra-oral: evidente dismorfia facial, com tumefação volumosa, mole à palpação, envolvendo o ramo mandibular esquerdo. Ao exame objetivo intra-oral: ausência do dente 38 na arcada dentária inferior e rebordo alveolar com mucosa de aspeto normal. Fazia-se acompanhar de Ortopantomografia, com um ano de evolução, onde era aparente uma 'imagem radiolucente, de carácter multilocular, tipo 'bolas de sabão', envolvendo o dente 38'.

Discussão e conclusões: O Ameloblastoma Multiquístico ocorre em $~ 80-85 \%$ dos casos na mandíbula e, ainda que sem predileção por género, parece ser mais frequente em indivíduos de raça negra. É um tumor geralmente assintomático - a dor é um achado incomum. Se não for tratado, pode atingir proporções grotescas. Em alguns casos, um dente não erupcionado - comummente um terceiro molar inferior - está associado ao defeito radiolúcido. Esta é, portanto, uma condição que pode ter um desfecho fatal para o doente, por ser uma lesão persistente e infiltrativa.

http://doi.org/10.24873/j.rpemd.2017.12.081

\section{\#054 Casos clínicos de extrações seriadas} - critérios de decisão

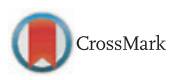

Helena Maltez Rodrigues, Berta Meireles, Eugénio Martins, Maria Cristina Figueiredo Pollmann*, Jorge Dias Lopes, Maria João Ponces

Faculdade de Medicina Dentária da Universidade do Porto

Introdução: As extrações seriadas constituem uma terapêutica ortodôntica amplamente utilizada e aceite, que visa intercetar precocemente a discrepância dento-maxilar, dimi- 
nuindo a gravidade da má oclusão, favorecendo a saúde periodontal e diminuindo a probabilidade de inclusões dentárias. Este tipo de protocolo terapêutico está particularmente indicado em pacientes que reúnem sinais próprios: molares em Classe I, discrepância dentomaxilar grave, incisivos em leque (convergência radicular), biprotrusão e sobremordida vertical normal ou diminuída inseridos num quadro esquelético tipo Classe I.

Descrição dos casos clínicos: Caso 1: Paciente, género feminino, 8 anos, com resumo de diagnóstico: Classe I dentária e discrepância dentomaxilar grave. Fase intercetiva com extrações dentárias sequenciais em dentição mista, sendo, mais tarde complementada com aparelho ortodôntico fixo. Caso 2: Paciente, género feminino, 7 anos, com resumo de diagnóstico: Classe I dentária, incisivos maxilares com convergência radicular, discrepância dentomaxilar grave e esfoliação precoce dos caninos temporários. Foram realizadas extrações dentárias sequenciais, de forma a favorecer a erupção dentária em gengiva queratinizada.

Discussão e conclusões: As extrações programadas constituem um método de ortodontia intercetiva que implica uma monitorização cuidadosa e periódica. Este tipo de intervenção raramente proporciona relações oclusais ideais, acompanhando-se de um aumento da sobremordida vertical, um aprofundamento da curva de Spee, espaços remanescentes e inclinações axiais incorretas, principalmente dos dentes adjacentes aos locais das extrações. Apesar de, na grande maioria dos casos, este tipo de intervenção não invalidar a necessidade de tratamento ortodôntico posterior, diminui consideravelmente a gravidade e as sequelas da má oclusão por desarmonia dentomaxilar grave, nomeadamente favorece a saúde periodontal e reduz a probabilidade de inclusões dentárias. Um protocolo de extrações seriadas adequado, aplicado em casos devidamente selecionados e monotorizados, favorece a colocação da dentição e previne impactos estéticos desfavoráveis.

http://doi.org/10.24873/j.rpemd.2017.12.082

\#055 Frenectomia labial superior: a propósito de um caso clínico

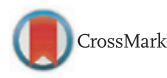

João Vitorino Santos*, Elisa Ribeiro Miranda, Rita Azevedo, Joana Loio, Paula Macedo, Casimiro de Andrade

\section{FMDUP}

Introdução: A frenectomia labial superior é efetuada por diversas razões, como por exemplo periodontal, ortodôntico e funcional.

Descrição do caso clínico: Paciente do sexo feminino, 14 anos de idade, recorreu a uma consulta na Faculdade de Medicina Dentária da Universidade do Porto por apresentar um diastema inter incisivo na arcada superior. Foi realizado o diagnóstico e plano de tratamento onde se optou pela Frenectomia Labial Superior seguida de Ortodontia Corretiva.

Discussão e conclusões: As duas técnicas ponderadas após o diagnóstico foram a cirurgia convencional e a utilização do laser. A técnica escolhida foi a cirurgia convencional. Serão descritos os princípios teóricos, a técnica utilizada, assim como os fatores de decisão da mesma. A frenectomia está in- dicada para a remoção das fibras interincisivas, uma vez que restabelece a fonética, a estética, melhora a auto-estima do paciente e previne os futuros espaços interincisivos. O momento da sua execução é decidido caso a caso dependendo do espaço previsto para os caninos.

http://doi.org/10.24873/j.rpemd.2017.12.083

\#056 Traumatismo dentário numa criança de 8 anos - Caso clínico

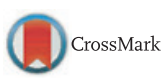

Ana Raquel Garcia Barata*, I. Ventura, G. Kizi, A. Albaladejo Martínez, D. Ribas, A. Castaño Seiquer

Egas Moniz Cooperativa de Ensino Superior, Portugal, Facultad de Odontologia, Universidad de Sevilla, Espanha, Facultad de odontologia, Universidad de Salamanca, Espanha, CiiEM - Centro de Investigação Interdisciplinar Egas Moniz

Introdução: Existe alguma variação entre os estudos quanto às causas predominantes do traumatismo dentário, contudo as quedas em casa e na escola são os fatores mais comuns tanto na dentição decídua como na permanente. Acidentes a praticar desporto, violência ou acidentes rodoviários são também causas bastante comuns no traumatismo dentário.

Descrição do caso clínico: Criança, sexo masculino, de 8 anos de idade em que o motivo da consulta foi 'caiu na escola e fraturou alguns dentes" SIC mãe. Foi reencaminhada para o departamento de Odontopediatria com traumatismo dentário dos dentes 3.2, 3.1, 4.1 e 4.2. Na análise clínica foi confirmado traumatismo dos dentes 3.1,3.2, 4.1 e 4.2, sendo que os dentes 3.1,3.2 e 4.2 apresentavam fratura do esmalte e da dentina. Os dentes 3.1 e 3.2 tinham sinais clínicos compatíveis com uma subluxação. Foram realizadas restaurações nos dentes com fratura e colocou-se uma contenção fixa para estabilizar os dentes durante duas semanas. Realizaram-se controlos radiográficos até um ano após o traumatismo.

Discussão e conclusões: O traumatismo dentário é considerado em todo o mundo um problema de saúde pública. Existe uma variação de estudos e países quanto à sua etiologia, contudo sabe-se que as quedas da escola e em casa são os fatores mais comuns. O desporto, a violência e os acidentes rodoviários são também considerados motivos frequentes de traumatismos. Neste caso clínico verificou-se que a intervenção imediata pode favorecer o prognóstico dos dentes que foram afetados por um traumatismo.

http://doi.org/10.24873/j.rpemd.2017.12.084

\section{\#057 Tratamento Interceptivo - a propósito} de um caso clínico

Joana Paiva Alves*, Telma Moreira, Mariana Seabra, Andreia Figueiredo

\section{Universidade Católica Portuguesa}

Introdução: A mordida cruzada anterior, definida pela palatino-versão de um ou mais dentes anteriores maxilares, é um tipo de má-oclusão que pode ser corrigida de forma inter- 